\title{
Avaliação dos riscos associados a alagamentos na planície costeira de Aracaju - SE, Brasil
}

\section{Evaluation of risk associated with flooding in coastal plains of Aracaju - SE, Brazil}

\author{
Luana Santos Oliveira Mota ${ }^{* 1} \bowtie\left(\mathbb{D}\right.$, Rosemeri Melo e Souza ${ }^{2} \bowtie(\mathbb{D}$ \\ 1Secretaria de Estado da Educação, do Esporte e da Cultura de Sergipe, Aracaju, Sergipe, Brasil \\ 2Departamento de Engenharia Ambiental, Universidade Federal de Sergipe, São Cristóvão, \\ Sergipe, Brasil \\ E-mail: rosemerimeloesouza@gmail.com \\ *E-mail para correspondência: oliveiras.lua@gmail.com
}

Recebido (Received): 08/10/2020

Resumo: A manutenção do delicado equilíbrio da paisagem costeira, revelado na complexidade dos seus componentes é dificultoso, principalmente quando se consideram os arranjos atuais de apropriação do espaço costeiro. Tal conjuntura tem propiciado o surgimento de diversos cenários de risco. Destarte, esse trabalho tem por escopo a avaliação dos riscos associados aos alagamentos para a planície costeira de Aracaju/SE, a partir da aplicação de uma metodologia fundamentada nas variáveis perigo (hidrometeorológico) e vulnerabilidade (exposição ao perigo). Os procedimentos metodológicos consistiram na avaliação e mensuração do perigo segundo a probabilidade de ocorrência, magnitude e suscetibilidade; da vulnerabilidade, baseado na estimativa da densidade de infraestrutura de drenagem e verificação das derivações antropogênicas, que permitem a análise da capacidade de suporte do ambiente; e do risco, a partir da interpolação dos indicadores de perigo e vulnerabilidade. Os resultados revelaram que cerca de $70 \%$ da planície costeira de Aracaju está associada a altos níveis de risco a alagamento. Esse cenário desponta onde se tem maior suscetibilidade natural aos alagamentos (baixios úmidos), ou quando há elevada derivação antrópica da paisagem e baixa capacidade de suporte da infraestrutura de drenagem pluvial, fato que altera bruscamente a capacidade de recuperação do ambiente e eleva os níveis de risco. Conclui-se, assim, que o risco tem sido produzido sistematicamente à medida que há o avanço desordenado da ocupação sobre unidades naturalmente suscetíveis, conjugado a contínua impermeabilização do solo e ausência de políticas públicas para gestão dos riscos.

Palavras-chave: Perigo hidrometeorológico; Vulnerabilidade; Derivações antropogênicas.

Abstract: The maintenance of the delicate balance of the coastal landscape, as evidenced by the complexity of its components, it's difficult, especially when considering the current arrangements for coastal grabbing. This situation has led to the emergence of several risk scenarios. Thus, this paper aims to assess the risks associated with flooding to the coastal plain of Aracaju/SE - Brazil, based on the application of a methodology supported on the variables hazard (hydrometeorological) and vulnerability (exposure to hazard). The methodological procedures consisted of assessing and measuring the hazard according to the probability of occurrence, magnitude and susceptibility; the vulnerability, based on an estimate of the density of drainage infrastructure and verification of anthropogenic derivations, which allow the analysis of the carrying capacity of the environment; and risk, by intertwining the indexes of hazard and vulnerability. The measurement of the indexes utilized revealed that about $70 \%$ of the coastal plain we have studied is associated with high levels of flooding risk. This scenario emerges where there is a greater natural susceptibility, or when there is high anthropic derivation of the landscape and a low capacity to support the rain drainage infrastructure, which is a fact that sharply alters the resilience of the environment and raises the risk levels. Thus, it is concluded that the risk has been systematically produced as there is a disorderly advance of occupation of naturally susceptible areas, combined with the continuous waterproofing of the soil and the absence of public policies for risk management.

Keywords: Hydrometeorological hazard; Vulnerability; Anthropogenic derivations. 


\section{Introdução}

As intensas transformações guiadas pelo componente antrópico nos sistemas naturais nos últimos séculos têm obstaculizado a manutenção de uma situação de equilíbrio, o que tem acarretado uma série de impactos nas mais diversas escalas. Ainda que os sistemas naturais possuam regras que ultrapassem a capacidade humana de influência, a alteração do equilíbrio dos sistemas naturais é manifestada principalmente na meso e microescala.

É desse contexto que desponta o conceito risco. Não obstante o uso nas mais diversas áreas das ciências e a existência de distintas conceitualizações, a sua definição é centralizada em torno do ideário de incerteza, probabilidade, perdas e prejuízos (CASTRO, 2000; CERRI; AMARAL, 1998; GIDDENS, 1991; HOLLNAGEL, 2008; SMITH; PETLEY, 1991; UNDRO, 1979; VEYRET, 2013; PEDUZZI, 2019). É de suma importância destacar que à medida que se discute o risco há outros conceitos que são complementares, a exemplo do perigo, da vulnerabilidade e dos desastres. Esses elementos são intrínsecos à concepção de risco, uma vez que este existe em função de um perigo, pode ter a possibilidade de ocorrência alargada pelo grau de vulnerabilidade de um dado ambiente ou população e, ao sair do campo da probabilidade e se concretizar, pode resultar em um desastre. Destarte, o risco é aqui entendido como produto da intersecção entre o perigo e a vulnerabilidade. O perigo é analisado dentro das dimensões temporal (probabilidade) e espacial (suscetibilidade) (JONES, 1993; SMITH, PETLEY, 1991; WHITE, 1974) e a vulnerabilidade a partir da análise das derivações antropogênicas da paisagem (MONTEIRO, 2001), da densidade das estruturas antrópicas (CUTTER, 1996; WISNER et al., 2003) e do grau de exposição (PEDUZZI, 2019).

No presente trabalho a avaliação do risco é estendida à paisagem costeira, mais especificamente o sistema ambiental da planície costeira. Caracterizada como um dos ambientes mais dinâmicos da terra, a zona costeira concentra grande parte da população mundial. De acordo com Bird (2008) mais metade da população mundial vive nesses ambientes, enquanto no Brasil mais da metade da população vive a menos de $200 \mathrm{~km}$ do litoral (MMA, 2002). Associada aos diferentes usos, a paisagem costeira ainda possui dinâmicas associadas aos elementos físicos que a constituem e modelam - a ação das ondas, das correntes costeiras, marés e ventos (SMITH; FITZGERALD, 1994; DAVIS; FITZGERALD, 2004).

Considerando a diversidade de unidades morfoesculturais associadas a zona costeira, emerge a necessidade da análise pormenorizada, tendo em vista que as características de cada ambiente irão definir, em parte, o grau de risco a um dado evento. Para o caso específico das planícies costeiras associadas a ambientes tectonicamente estáveis e não associadas a fenômenos climáticos de grandes proporções, a preocupação com os riscos associados à ocupação tende a ser reduzida uma vez que, aparentemente, suas consequências são mínimas em razão da magnitude dos perigos. Diferentemente, por exemplo, das costas associadas a serras ou falésias, cuja ocupação irregular associada a excessos pluviométricos potencializa os riscos associados ao deslizamento de terras, ou ainda, as zonas costeiras sujeitas a inundações por efeito de ciclones extratropicais, por exemplo. Nestes casos, os riscos são muito mais percebidos pela população, em razão da magnitude dos efeitos (VEYRET, 2013). Essa percepção errônea, para o caso das planícies costeiras destacadas, acaba por inibir a avaliação dos riscos e consequentemente a construção de políticas públicas eficientes.

Por essa razão, é precípuo que se considere que inobstante algumas planícies costeiras estejam associadas a eventos de menor magnitude espacial, pode ocorrer grande incidência temporal de determinados eventos perigosos, que necessitam ser considerados, principalmente quando se considera áreas extremamente antropizadas, fator substancial para a existência do risco, em áreas cujas feições são suscetíveis.

Nesse sentido faz-se analogia às acepções trazidas por Peduzzi (2019) ao considerar que certos desastres são resultantes do acúmulo de determinadas situações de risco ao longo do tempo, decorrentes de ações cotidianas após inadequadas decisões. Pode-se enquadrar nesse cenário os riscos associados aos perigos hidrometeorológicos nas planícies costeiras antropizadas. O elevado grau de derivação antropogênica, termo cunhado por Monteiro (2001) para referir-se a ambientes que tiveram sua estruturação alterada pela ação humana, reflete diretamente na capacidade de suporte dessa paisagem. A medida em que a paisagem tem sua estrutura e função alteradas, há possibilidade que o ambiente se torne incapaz de recobrar-se de eventos perigosos (RODRIGUEZ; SILVA; CAVALCANTI, 2004). Conectando-se as considerações de Peduzzi (2019) destaca-se que ausência de políticas públicas relacionados ao ordenamento territorial e ao planejamento ambiental, ao longo do tempo tem resultado nessa soma de situações que conduzem a cenários de risco.

Em face dessa conjuntura, o presente trabalho tem por objetivo a apresentação e aplicação de uma metodologia que objetiva avaliar e mensurar o risco associado a alagamentos em planícies costeiras, fundamentada no binômio perigo/vulnerabilidade. 


\section{Material e métodos}

\section{1. Área de estudo}

A área investigada no presente artigo compreende os bairros localizados na frente litorânea do município de Aracaju/SE: Coroa do Meio, Atalaia e Zona de Expansão (Figura 1). Tal município é composto por 40 bairros, com uma população estimada de 657.013 habitantes (IBGE, 2019) e área de $181.857 \mathrm{~km}^{2}$. Ressaltase que não obstante o recorte realizado para compor o objeto de estudo, todo o município de Aracaju está associado ao que se entende por Zona Costeira, levando em consideração os parâmetros estabelecidos pelo Plano Nacional de Gerenciamento Costeiro.

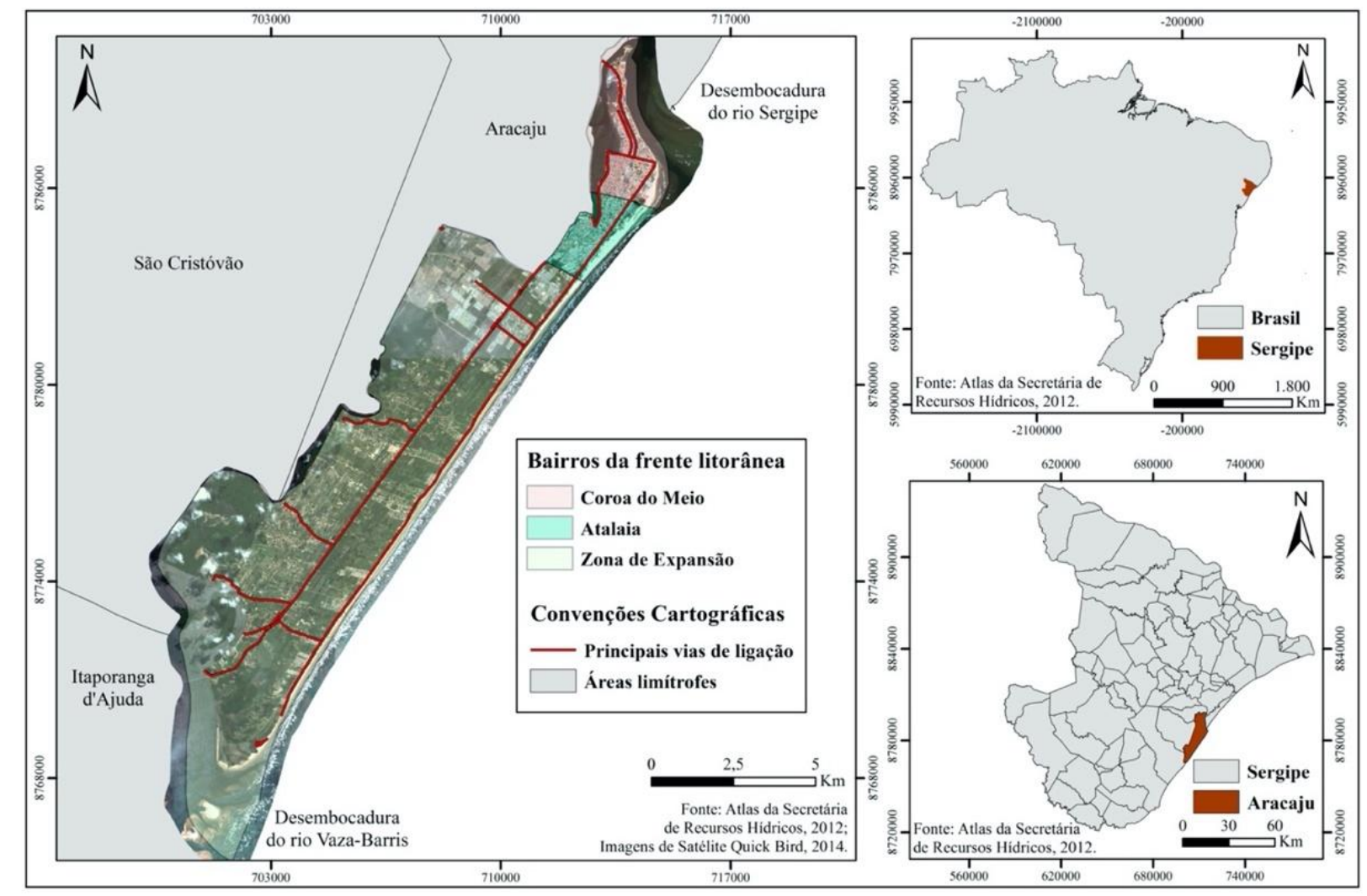

Figura 1: Localização da área de estudo. Fonte: Elaboração das autoras, 2020.

Observa-se na cidade de Aracaju um reordenamento da ocupação da frente litorânea, movido pela intensa especulação imobiliária, o que tem acarretado grandes transformações na composição biofísica desse ambiente.

Como destaca Ribeiro (1985), até a década de 1960 a frente litorânea do munícipio constituía área de reserva à expansão, praticamente inabitada, uma vez que a maior concentração populacional se restringia à região estuarina do rio Sergipe, mais especificamente à sua margem direita. Apenas no período que compreendeu meados da década de 1960 e década de 1970, foi evidenciado fluxo populacional em direção, inicialmente, aos bairros Atalaia e Coroa do Meio (NOGUEIRA, 2004).

Após as constantes intervenções urbanísticas e fixação da população nos referidos bairros, em meados da década de 1980, inaugurou-se nova fase de ocupação da orla costeira, marcada pela reorientação do fluxo populacional em direção aos espaços não ocupados localizados ao sul da cidade - a Zona de Expansão (MACHADO, 1989; FRANÇA; REZENDE, 2010; VILAR, 2010).

Todo o processo descrito foi orientado pela ação conjunta entre poder público e privado, cujas ações foram pautadas na crescente valorização do solo nos bairros costeiros e na exploração dos seus valores paisagísticos (MACHADO, 1989). O poder público proporcionou a instalação de infraestrutura, ainda que deficiente, para os bairros destacados, o que propiciou a atuação massiva do setor imobiliário. Importantes eixos viários de comunicação entre toda a frente litorânea da cidade foram construídos/reestruturados, a exemplo da antiga rodovia José Sarney (atual Av. Inácio Barbosa) construída ainda na década de 1980 à beira mar. Tal eixo permitiu o desenvolvimento da área compreendida entre essa e a rodovia dos Náufragos, 
que resultou na criação de novos loteamentos e construção de condomínios, além de ter dinamizado a orla costeira de Aracaju através do turismo e da construção de edificações à beira mar.

A conjugação de todos os fatores aqui citados, resultou num acréscimo populacional nos bairros estudados. A título de exemplificação, entre as décadas de 2000 e 2010 houve aumento populacional de $25 \%$ no bairro Coroa do Meio, de $27 \%$ no bairro Atalaia e de 33\% na Zona de Expansão (IBGE, 2010). Identificase assim que frente litorânea se encontra em pleno processo de transição, haja vista que historicamente a maior concentração populacional do munícipio esteve associada a região estuarina do rio Sergipe.

O óbice da evolução da ocupação desses bairros é que o aumento populacional não foi acompanhado de infraestruturas urbanas adequadas, com destaque para rede de esgotamento e de drenagem das águas pluviais, principalmente na Zona de Expansão. Além disso há de se destacar que o contínuo aumento de área ocupada se deu a partir de supressão das unidades naturais, parte delas responsáveis pela drenagem natural da área. A julgar pelo intenso processo de ocupação e pelos impactos já causados, evidencia-se a preocupação com a capacidade do ambiente costeiro em suportar tal intervenção sem ter todas as suas características suprimidas.

Quanto à estruturação natural da paisagem costeira de Aracaju, destaca-se a presença das seguintes unidades geomorfológicas: terraço marinho entremeados por uma sequência bem marcada de cordões litorâneos, os quais evidenciam o caráter progradacional da costa aracajuana; dunas fixas e semifixas, que espraiam-se sobre toda a frente litorânea; planícies de maré, associadas às desembocaduras dos rios Sergipe e Vaza-Barris, recobertas pela vegetação de mangue; e lagoas e baixios úmidos, presentes em quase toda a extensão da área estudada.

É sobre esse conjunto de unidades, cuja análise geoecológica aponta para a elevada suscetibilidade natural, que tem se estabelecido cenário de aumento populacional e de área ocupada. Tal fato tem potencializado os riscos, associados primordialmente ao processo de urbanização desordenado e não planejado. Uma das situações resultantes dessa conjuntura, são os riscos associados aos alagamentos, foco do presente estudo.

\subsection{Procedimentos metodológicos}

A Figura 2 traz a matriz de avaliação de risco, cuja construção fundamentou-se em dois conceitos: perigo e vulnerabilidade. O perigo, no âmbito da presente pesquisa, foi conjecturado a partir de três ângulos: a probabilidade de ocorrência - que tem relação com a incidência temporal de um processo perigoso; a intensidade - definida pela magnitude; e a suscetibilidade - cuja avaliação está relacionada a propensão que uma dada área apresenta de ser afetada por um processo perigoso.

O perigo destacado nessa pesquisa foram os alagamentos resultantes de eventos pluviométricos concentrados - perigos hidrometeorológicos.

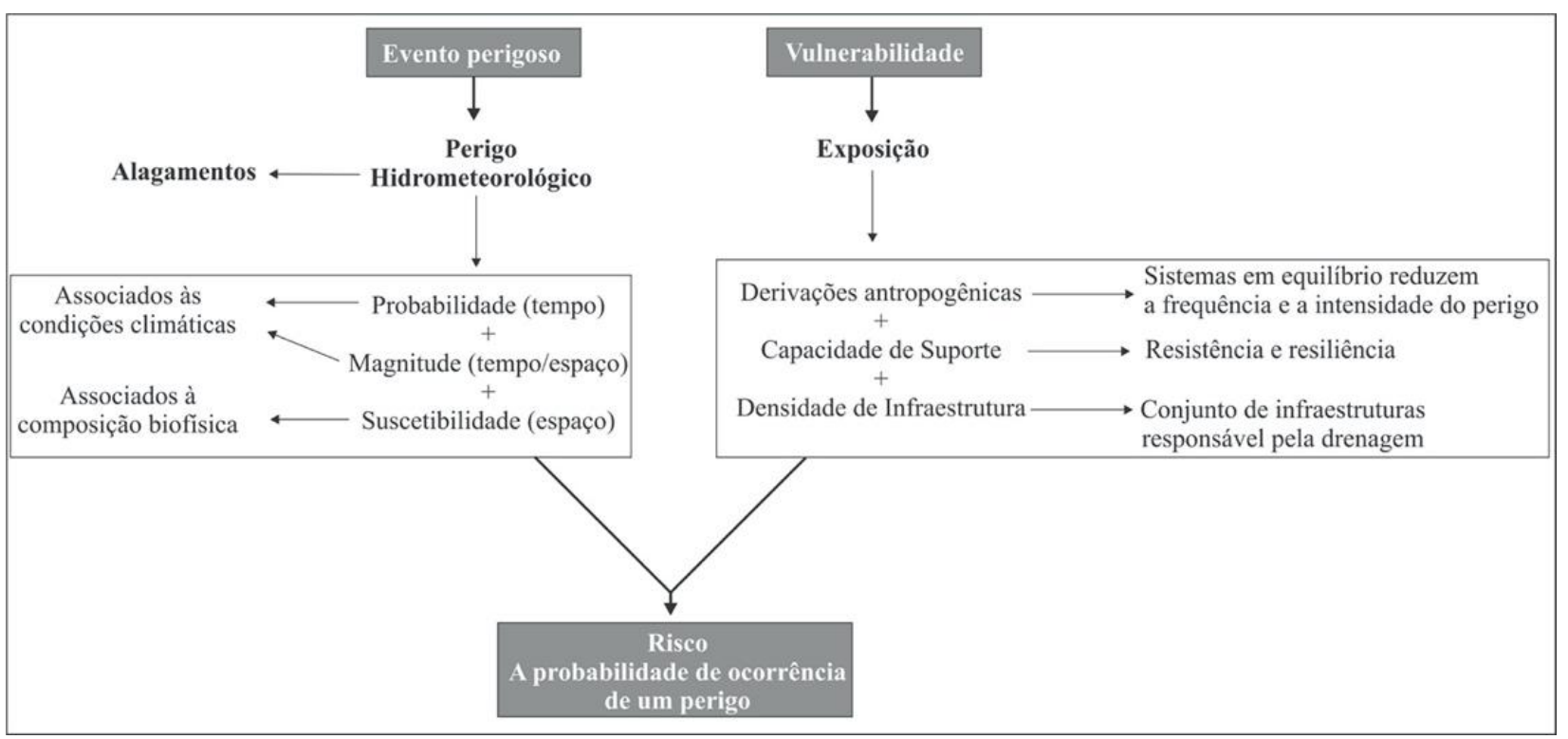

Figura 2: Matriz de avaliação do risco para a zona costeira. Fonte: Elaboração das autoras, 2020. 
A vulnerabilidade foi aqui considerada segundo as acepções de Wisner et al., (2003), o qual se faz em três perspectivas: a causa raiz (root cases) - que se relaciona aos aspectos históricos, políticos e demográficos; as pressões dinâmicas (dynamic pressures) - interligado a determinados processos, como o exemplo da urbanização acelerada; e as condições de insegurança (unsafe conditions) - que faz alusão aos condicionantes que levam à exposição a determinados perigos. Dentro dessa última categoria, inclui-se o conceito de capacidade de suporte, trazido por Mendes; Tavares (2009), Mendes et al., (2011) e Cunha (2013) os quais o definem como um conjunto de infraestruturas que permite a comunidade reagir diante da ocorrência de eventos perigosos.

É acrescido a essas considerações o conceito de Derivações Antropogênicas da Paisagem de Monteiro (2001) associado, mormente, às mudanças na cobertura do solo que conduzem a alterações na estruturação da paisagem. Dentro dos preceitos aqui trabalhados, considera-se que a maior exposição da população a eventos perigosos está intimamente relacionada com a não capacidade adaptativa da população, que pode estar correlacionada tanto as condições socioeconômicas quanto a ausência de uma rede de infraestrutura capaz de absorver os impactos resultantes dos excessos pluviométricos.

\subsubsection{Avaliação do perigo}

- Análise da magnitude e da probabilidade temporal de incidência do evento perigoso: examinou-se nesta etapa qual a probabilidade temporal de ocorrência do perigo considerado tal como a sua magnitude. A análise de dados históricos referentes às precipitações foi a opção escolhida para avaliação de ambos. Foi realizada busca dos dados climáticos no Banco de Dados Meteorológicos para Ensino e Pesquisa do Instituto Nacional de Meteorologia - INMET. Adotou-se como escala temporal de análise um período de 53 anos (1961-2014). Identificou-se assim o período de maior concentração pluviométrica, tal como a magnitude desses eventos.

- Determinação da suscetibilidade aos alagamentos: o cálculo da suscetibilidade a alagamentos teve por área base as unidades e subunidades geoecológicas da área de estudo, quais sejam: Terraço Marinho, Campo de Dunas, Depósitos dos Bancos Arenosos Coalescidos, Planície de Maré, Ambientes de Sedimentação Recente, Depósitos Tecnogênicos (Figura 3), definidas por MOTA; SOUZA (2017). Os indicadores utilizados para a construção da matriz de mensuração da suscetibilidade foram a intensidade pluviométrica, a pedologia, a geomorfologia (topografia) e a cobertura do solo, com o emprego da escala de valores variando entre 0 e 10 (Tabela 1). O cálculo da suscetibilidade foi realizado por média simples, optou-se em não usar a média ponderada tenho em vista que os indicadores utilizados possuem importância semelhantes quando relacionados aos perigos hidrometeorológicos.

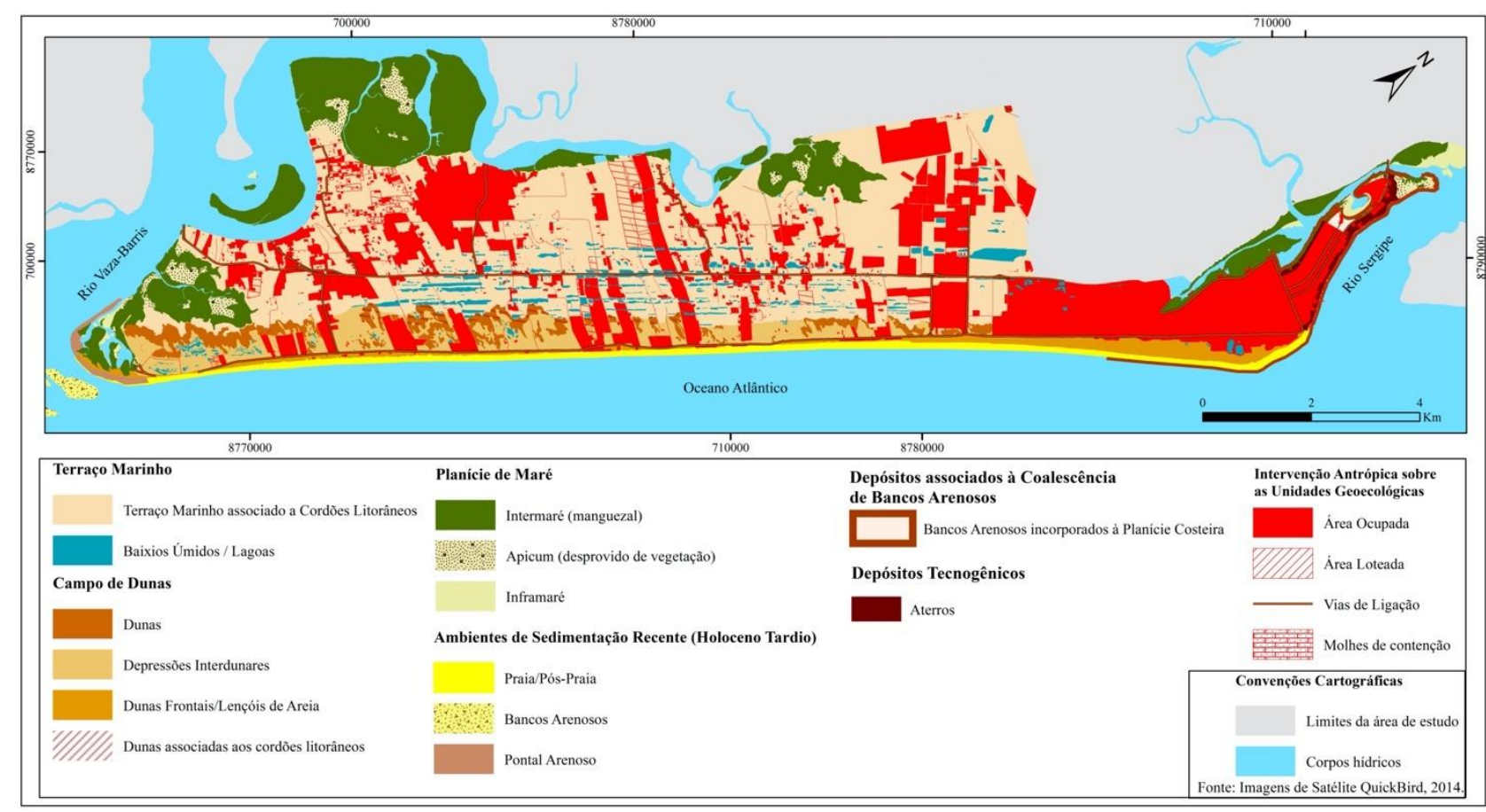

Figura 3: Unidades Geoecológicas da planície costeira de Aracaju/SE. Fonte: Mota; Souza, 2017. 
Tabela 1: Indicadores para mensuração da suscetibilidade a alagamentos.

\begin{tabular}{|c|c|c|c|c|c|c|}
\hline Indicadores & Parâmetros & \multicolumn{5}{|c|}{ Valores adotados } \\
\hline \multirow{2}{*}{$\begin{array}{l}\text { Concentração } \\
\text { pluviométrica }\end{array}$} & \multirow[t]{2}{*}{ Intensidade* } & 1: $<50 \mathrm{~mm}$ & $\begin{array}{c}\text { 2: } 51-100 \\
\mathrm{~mm}\end{array}$ & $\begin{array}{c}\text { 3: } 101-150 \\
\mathrm{~mm}\end{array}$ & $\begin{array}{c}\text { 4: } 151-200 \\
\mathrm{~mm}\end{array}$ & $\begin{array}{c}\text { 5: } 201-250 \\
m m\end{array}$ \\
\hline & & $\begin{array}{c}\text { 6: } 251-300 \\
\mathrm{~mm}\end{array}$ & $\begin{array}{c}\text { 7: } 301-350 \\
\mathrm{~mm}\end{array}$ & $\begin{array}{c}8351-400 \\
\mathrm{~mm}\end{array}$ & $\begin{array}{c}\mathbf{9}: 400-450 \\
\mathrm{~mm}\end{array}$ & $\begin{array}{c}\text { 10: }>450 \\
\mathrm{~mm}\end{array}$ \\
\hline Pedologia & $\begin{array}{l}\text { Drenagem do } \\
\text { solo** }\end{array}$ & \multicolumn{5}{|c|}{$\begin{array}{l}\text { 1: Solos excessivamente drenados; 2: fortemente drenados; 3: } \\
\text { acentuadamente drenados; 4: bem drenados; 5: moderadamente drenados; } \\
\text { 7:imperfeitamente drenados; } 8 \text { : mal drenados; 10: muito mal drenado }\end{array}$} \\
\hline $\begin{array}{c}\text { Geomorfologia } \\
\text { (Topografia) }\end{array}$ & $\begin{array}{c}\text { Variação } \\
\text { altimétrica*** }\end{array}$ & $\mathbf{1}:>15 \mathrm{~m}$ & $\begin{array}{c}\text { 3: entre } 10 \mathrm{e} \\
15 \mathrm{~m}\end{array}$ & 5: $10 \mathrm{~m}$ & $\begin{array}{c}\text { 7: entre } 5 \mathrm{e} \\
10 \mathrm{~m}\end{array}$ & 10: $<5 \mathrm{~m}$ \\
\hline \multirow[t]{2}{*}{ Cobertura do solo } & \multirow{2}{*}{$\begin{array}{c}\text { Total de área } \\
\text { ocupada }\end{array}$} & 1: $<10 \%$ & 2: 11 a $20 \%$ & $\begin{array}{l}\text { 3: de } 21 \text { a } \\
30 \%\end{array}$ & $\begin{array}{l}\text { 4: de } 31 \text { a } \\
40 \%\end{array}$ & $\begin{array}{l}\text { 5: de } 41 \mathrm{a} \\
50 \%\end{array}$ \\
\hline & & $\begin{array}{c}\text { 6: de } 51 \text { a } \\
60 \%\end{array}$ & $\begin{array}{c}\text { 7: de } 61 \text { a } \\
70 \%\end{array}$ & $\begin{array}{c}\text { 8: de } 71 \text { a } \\
80 \%\end{array}$ & $\begin{array}{l}\text { 9: de } 81 \text { a } \\
90 \%\end{array}$ & 10: $>90 \%$ \\
\hline \multicolumn{2}{|c|}{ Cálculo final } & \multicolumn{3}{|c|}{$\begin{array}{l}\text { Onde, } \\
\mathrm{S}_{\mathbf{a}}=\left(\mathbf{C}_{\mathbf{p}}+\mathbf{P}+\mathbf{G}+\mathbf{C}_{\mathbf{s}}\right) / \mathbf{4} \\
\mathrm{C}_{\mathrm{p}}=\text { Concetibilidade a alagamentração pluviométrica } \\
\mathrm{P}=\text { Pedologia } \\
\mathrm{G}=\text { Geomorfologia } \\
\mathrm{C}_{\mathrm{s}}=\text { Cobertura do solo }\end{array}$} & \multicolumn{2}{|c|}{$\begin{array}{c}\text { Suscetibilidade baixa: }<3,5 \\
\text { Suscetibilidade média: } \\
3,6-7,0 \\
\text { Suscetibilidade alta: }>7,0\end{array}$} \\
\hline
\end{tabular}

* Valores fundamentados na obra de Crepani et al., (2001). ** Classes de drenagem definidos pelo Manual Técnico de Pedologia IBGE (2007). *** Topografia avaliada com base na diferenciação altimétrica da área de estudo.

Fonte: Elaboração das autoras, 2020.

Para confecção do mapa de suscetibilidade utilizou-se o método de interpolação IDW (ponderação do inverso das distâncias) através da ferramenta do ArcTollbox "Spatial Analyst Tools - Interpolation" (via programa de geoprocessamento ArcGIS). Todos os mapas apresentados foram construídos com base no sistema de projeção Universal Transversa de Mercator - UTM e o datum SIRGAS BRASIL 2000.

Destaca-se que para avaliação do indicador pedologia, utilizou-se o Mapa de Solos da Embrapa elaborado para o estado de Sergipe associado aos resultados obtidos por Mota; Souza (2018) no que concerne às classificações dos depósitos tecnogênicos presentes em parte da área de estudo.

Os valores adotados para drenagem de solos foram adaptados às categorias de solos delimitadas IBGE (2007), que perfazem 8 classes. Por essa razão dois valores (6 e 9) foram suprimidos. Mesma lógica foi seguida na atribuição dos valores ao indicador topografia, uma vez que a reduzida variação de altitude não permitiu a classificação em 10 categorias, optou-se pela escolha de valores intermediários $(1,3,5,7$ e 10).

\subsubsection{Avaliação da vulnerabilidade das ocupações aos alagamentos}

Para esse indicador considerou-se o nível de derivação da paisagem e a capacidade de suporte das ocupações diante de eventos pluviométricos concentrados. Relacionado ao nível de derivação, estima-se que quanto maior for o processo de derivação da paisagem (considerando as intervenções desordenadas que ocorreram), menor a capacidade do ambiente em se recuperar de um evento perigoso. Já em relação à capacidade de suporte, foi apreciado a disponibilidade de infraestrutura, com realce para as redes de micro e macrodrenagem e para rede de esgotamento. De tal modo, é avaliado o agrupamento populacional que pode vir a ser afetado pelo perigo hidrometeorológico, fato que está correlacionado com a maior ou menor capacidade de recuperação do ambiente.

Os valores adotados para mensuração estão evidenciados na Tabela 2. O cálculo ora apresentado diverge dos demais, haja vista ter-se optado pelo uso de pesos para os indicadores. Justifica-se tal escolha, uma vez que para o caso particular dos alagamentos, a existência de redes de drenagem e o nível de derivação da paisagem constituem indicadores mais significativos que a rede de esgotamento. 
Tabela 2: Mensuração da vulnerabilidade a eventos perigosos.

\begin{tabular}{|c|c|c|}
\hline \multicolumn{2}{|r|}{ Indicadores da Capacidade de Suporte } & Grau de Vulnerabilidade \\
\hline $\begin{array}{l}\text { Nível de derivação } \\
\text { da paisagem (NDP) }\end{array}$ & $\begin{array}{l}\text { 1: Muito baixo; 3: Baixo; 5: Médio; 7: Alto; 10: Muito } \\
\text { alto. }\end{array}$ & \multirow{3}{*}{$\begin{array}{l}\text { V }=(0,4 \text { x NDP })+(0,2 \times \mathrm{TE}) \\
+(0,4 \times \mathrm{RMiMa}) \\
\text { Vulnerabilidade muito baixa: } \\
<2,0 \\
\text { Vulnerabilidade baixa: } \\
2,0-4,0 \\
\text { Vulnerabilidade média: } \\
4,1 \text { a } 6,0 \\
\text { Vulnerabilidade alta: } \\
6,1 \text { a } 8 \\
\text { Vulnerabilidade muito alta: } \\
>8,0\end{array}$} \\
\hline $\begin{array}{l}\text { Tipo de } \\
\text { Esgotamento (TE) }\end{array}$ & $\begin{array}{l}\text { 1: Predomínio de rede geral } \\
\text { 3: Rede geral (até } 70 \%)+ \text { outros mecanismos (até 30\%) } \\
\text { 5: Rede geral (até } 50 \%)+ \text { Fossas sépticas e rudimentares } \\
\text { (cerca até } 50 \% \text { ) } \\
\text { 7: Predomínio de fossas sépticas e rudimentares (mais de } \\
\text { 70\%) } \\
\text { 10: Vala, rio, mar, lago }\end{array}$ & \\
\hline $\begin{array}{l}\text { Rede } \\
\text { de Micro e } \\
\text { Macrodrenagem } \\
\text { (RMiMa) }\end{array}$ & $\begin{array}{l}\text { 1: Micro e macrodrenagem existentes: } \\
\text { 3: Micro e macrodrenagem com cobertura parcial (mais } \\
\text { de } 70 \% \text { da área) } \\
\text { 5: Micro e macrodrenagem existentes com falhas } \\
\text { 7: Apenas microdrenagem } \\
\text { 10: Micro e macrodrenagem inexistentes }\end{array}$ & \\
\hline
\end{tabular}

Fonte: Elaboração das autoras, 2020.

\subsubsection{Mensuração e delimitação das áreas de risco}

Com respaldo nos valores obtidos para os indicadores de perigo e vulnerabilidade, foi calculado o risco para os alagamentos. A fórmula para a mensuração adotada na presente pesquisa derivou dos preceitos trazidos pelos autores Wisner et al., (2004), Garcia; Zêrere (2003); Freiria; Cunha; Santos (2009) e Peduzzi (2019), conforme exposto na equação abaixo:

$$
\frac{\mathrm{R}=(\mathrm{P}+\mathrm{V})}{2}
$$

Onde,

$\mathrm{R}=$ Risco; $\mathrm{P}=$ Perigo $; \mathrm{V}=$ Vulnerabilidade

Sublinha-se que não obstante o risco possuir um caráter manifestamente quantitativo, a avaliação aqui realizada foi entremeada também por uma análise qualitativa, uma vez que nem tudo aquilo que está associado ao risco pode ser precisamente quantificado.

Os estágios utilizados para mensurar o risco estão expostos na Tabela 3.

Relacionado à construção dos mapas de riscos adotou-se o método de interpolação - IDW, para o qual seguiram-se as mesmas etapas descritas anteriormente.

Tabela 3: Mensuração do risco associado aos alagamentos.

\begin{tabular}{|c|c|c|c|c|c|}
\hline $\begin{array}{l}\text { Probabilidade/ } \\
\text { Magnitude (P) }\end{array}$ & $\begin{array}{c}\text { Suscetibilidade } \\
\text { (S) }\end{array}$ & $\begin{array}{c}\text { Índice de } \\
\text { Perigo }\left(P_{e}\right)\end{array}$ & Vulnerabilidade (V) & $\begin{array}{l}\text { Índice de } \\
\text { risco }(R)\end{array}$ & Grau do risco \\
\hline $\begin{array}{l}\text { 1: Baixo } \\
\text { 5: Médio } \\
\text { 10: Alto }\end{array}$ & $\begin{array}{l}<2: \text { Muito baixo } \\
\text { 2- 4: Baixo } \\
\text { 4,1 - 6: Médio } \\
\text { 6,1 - 8: Alto } \\
>\text { 8: Muito alto }\end{array}$ & $\mathrm{P}_{\mathrm{e}}=(\mathrm{P}+\mathrm{S}) / 2$ & $\begin{array}{c}\text { <2: Muito baixo } \\
\text { 2 - 4: Baixo } \\
\text { 4,1 - 6: Médio } \\
\text { 6,1 - 8: Alto } \\
>\text { 8: Muito alto }\end{array}$ & $\mathrm{R}=\left(\mathrm{P}_{\mathrm{e}}+\mathrm{V}\right) / 2$ & $\begin{array}{c}<2: \text { Muito baixo } \\
\text { 2 - 4: Baixo } \\
\text { 4,1 - 6: Médio } \\
\text { 6,1 - 8: Alto } \\
>\text { 8: Muito alto }\end{array}$ \\
\hline
\end{tabular}

Fonte: Elaboração das autoras, 2020

\section{Resultados e discussão}

\subsection{Probabilidade de ocorrência, intensidade e suscetibilidade a alagamentos}

Nos bairros costeiros estudados - Coroa do Meio, Atalaia e Zona de Expansão, os alagamentos decorrem da conjunção de duas razões: os eventos pluviométricos intensos e ausência de infraestrutura urbana adequada. 
Relacionado aos eventos pluviométricos, efetuou-se análise da média histórica da precipitação municipal referente às últimas cinco décadas, a fim de delimitar a probabilidade de ocorrência, tal como a intensidade dos eventos chuvosos (Figura 4).

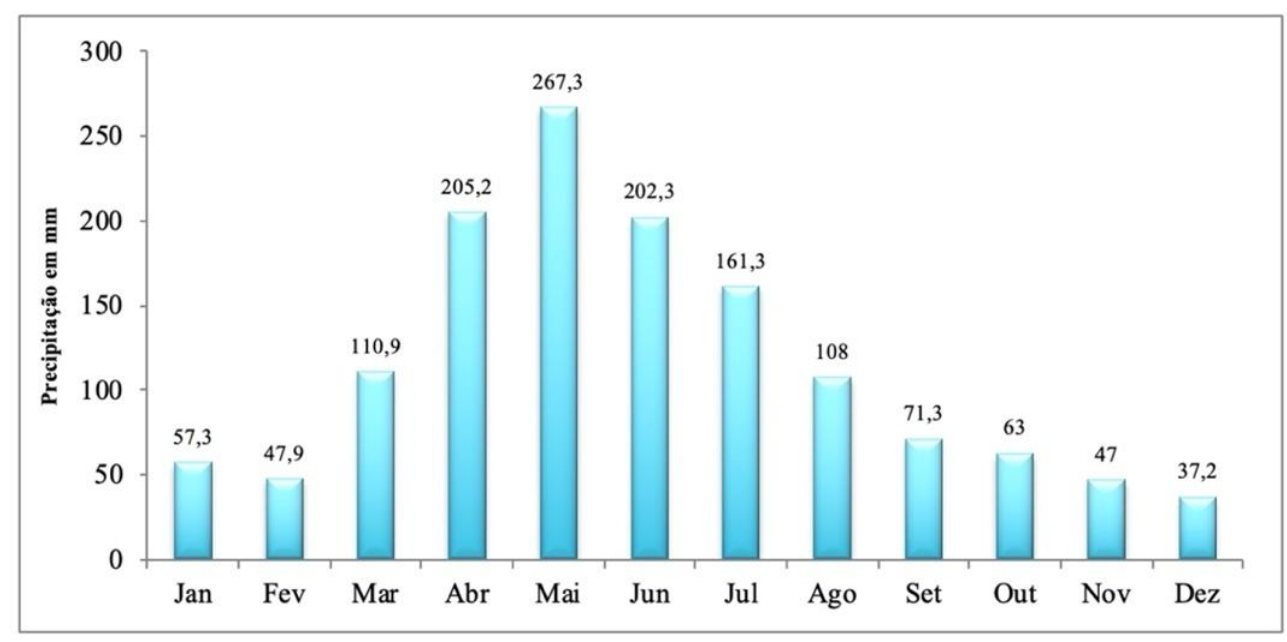

Figura 4: Precipitação média mensal do município de Aracaju/SE entre 1961 e 2015. Fonte: Dados da rede do INMET. Organização das autoras, 2020.

Os dados revelaram que o período mais chuvoso de Aracaju ocorre entre abril e julho, quando a precipitação média excede os $160 \mathrm{~mm}$ mensais. Destaque para o mês de maio, cuja precipitação supera todos os outros meses do ano. De tal modo, seguindo a tendência observada para o clima litorâneo úmido, a maior probabilidade de ocorrência dos eventos pluviométricos está associada ao período de outono-inverno, que também é marcado pela maior intensidade das chuvas. Já os meses de agosto a março marcam o período mais seco, onde os eventos pluviométricos acontecem de forma esporádica, associados a chuvas convectivas.

Relativo ao indicador suscetibilidade foram avaliados os elementos da paisagem que atestam a predisposição dessa à ocorrência de alagamentos. São estes: a concentração pluviométrica, a composição pedológica, a topografia e a cobertura do solo. Na Tabela 4 estão expostos os valores atribuídos a cada indicador, já a espacialização desses dados está em evidência na Figura 5.

No que pertence ao indicador climático, aplicou-se o conceito de intensidade pluviométrica trazida por Crepani et al., (2001) no qual é calculado a razão entre a pluviosidade média anual e a duração do período chuvoso, tal como exposto na tabela 4.

Quanto à composição pedológica, considerou-se como indicador a drenagem do solo, a qual se associa à capacidade de infiltração e/ou escoamento da água (Tabela 4). Os solos do tipo Espodossolos são predominantes na área estudada, associados aos terraços marinhos, que se enquadram na categorial de mal drenados. A despeito do solum possuir textura essencialmente arenosa, estes solos possuem um horizonte B espódico que dificulta a infiltração. Ademais, a presença do lençol freático mais próximo à superfície em alguns pontos, ocasionam a saturação do solo mais rapidamente.

Há ainda os solos que se caracterizam por estarem frequentemente ou periodicamente alagados, a exemplo dos solos associados aos baixios úmidos e lagoas; e a planície de maré. Tal circunstância inclui esses ambientes como os mais suscetíveis a alagamentos, uma vez que a frequente saturação obstaculiza a infiltração.

Com dinâmica oposta ao apontado anteriormente tem-se os Neossolos Quartzarênicos, componente dos campos dunares e do ambiente praial. Esses caracterizam-se pela rápida infiltração, ligada a textura majoritariamente arenosa. Logo, é o solo que apresenta menor suscetibilidade aos alagamentos dentro da área investigada. 
Tabela 4: Mensuração da suscetibilidade a alagamentos.

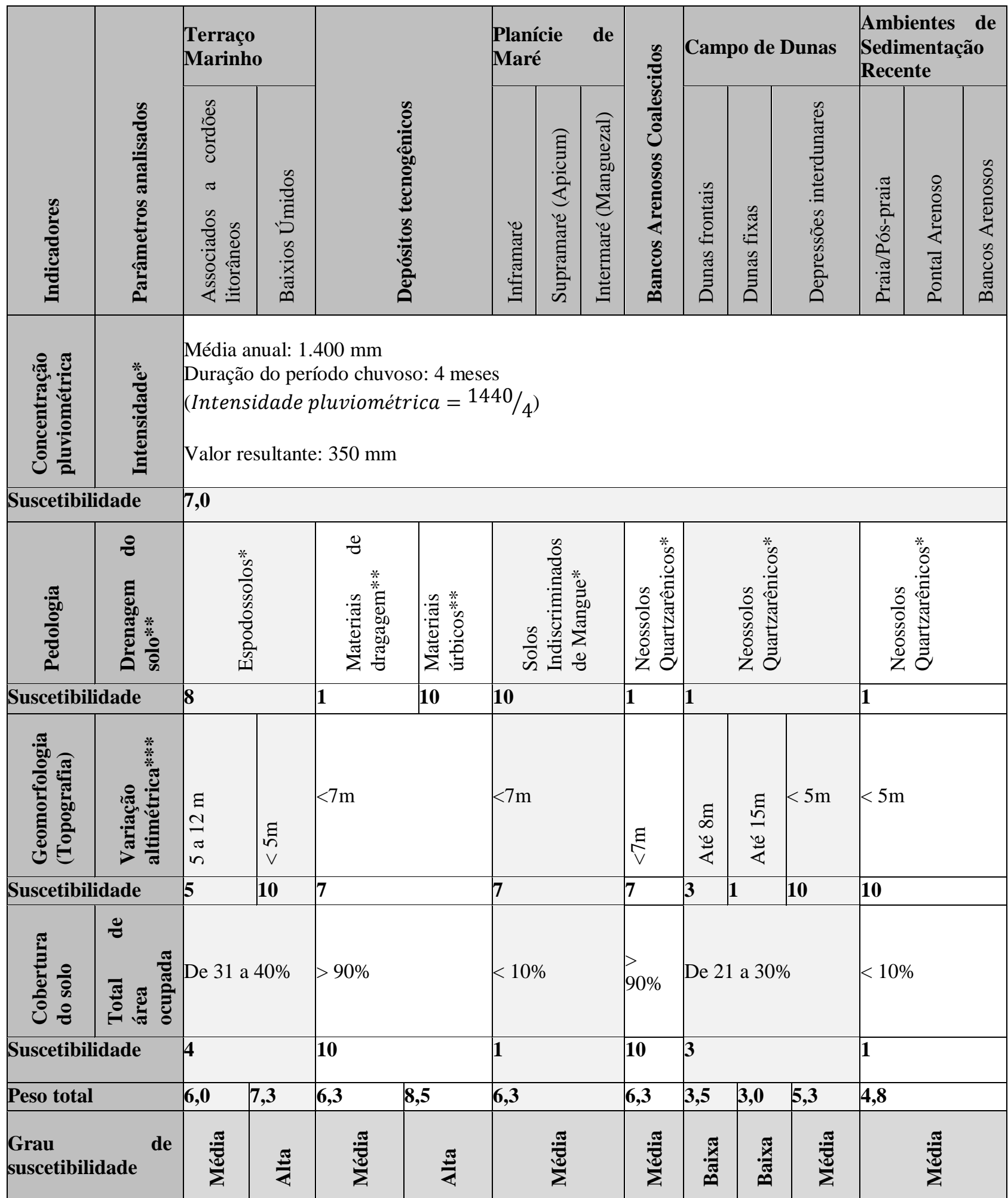

* Solos identificados pela EMBRAPA (2006); ** Solo identificado por sondagem (MOTA; SOUZA, 2018). Fonte: Elaboração das autoras.

Faz-se ressalva quanto a uma área restrita, localizada no bairro Coroa do Meio, cuja composição pedológica foi completamente alterada pela ação antrópica através da realização de aterros. Mota; Souza (2018) definiram e classificaram esses depósitos enquanto tecnogênicos, e apontaram para a existência de duas fases de aterro que resultaram numa estruturação diferenciada. Enquanto o primeiro aterro foi realizado com sedimentos predominantemente arenosos, oriundos da dragagem de um canal (materiais dragados), o segundo aterro foi executado com restos de construção e detritos de origem antrópica, associados a materiais com predominância de argila e silte (materiais úrbicos) (MOTA; SOUZA, 2018). Ainda que o Manual Técnico de Pedologia do IBGE (2007) não enquadre solos alterados pela ação antrópica dentro da classificação de drenagem, optou-se pela realização de uma classificação análoga. De tal modo, os solos relacionados à segunda fase do aterro, que possuem uma primeira camada de classificação textural franco- 
argilosa, foram enquadrados como solos muito mal drenados, uma vez que este aspecto textural dificulta a infiltração. Já aqueles solos relacionados à primeira fase do aterro foram classificados como solos excessivamente drenados, pela constituição predominantemente arenosa.

Atinente à geomorfologia, utilizou-se como indicador a topografia, pois este influencia tanto na velocidade do escoamento, quanto na capacidade de armazenamento. Os bairros estudados estão assentados sobre uma planície costeira e uma planície fluviomarinha com baixas amplitudes altimétricas. Embora esses valores sejam reduzidos, eles são importantes para a estimativa da suscetibilidade, devido ao fluxo do escoamento ser guiado fundamentalmente pela ação da gravidade. A variação altimétrica detectada para as planícies costeira e fluviomarinha foi de 0 a 15 metros, em função da qual se definiu os índices de suscetibilidade (Tabela 4).

Para o último indicador, a cobertura do solo, foi examinado a porcentagem de ocupação sobre as unidades (Tabela 4). É nesse indicador que as derivações antrópicas são mais percebidas em razão da constante impermeabilização do solo e consequente retirada da vegetação, sobretudo por efeito do aumento de área ocupada. O que se observa é a existência de uma relação inversamente proporcional entre escoamento superficial e infiltração, que é altamente dependente das mudanças no uso e ocupação do solo.

A análise conjunta dos dados revela que as áreas associadas ao grau baixo de suscetibilidade a alagamentos restringiram-se às dunas frontais e fixas em razão da composição pedológica e, primordialmente, por suas formas onduladas que ocasionam a baixíssima retenção de água.

Mediante a espacialização dos dados identificou-se que as áreas que possuem os menores índices de suscetibilidade aos alagamentos, estão associadas aos campos dunares e ao ambiente praial (Figura 5). Isso se deve em razão da conjunção de fatores como: elevada capacidade de drenagem do solo, os medianos índices de cobertura do solo e a própria topografia do campo dunar.

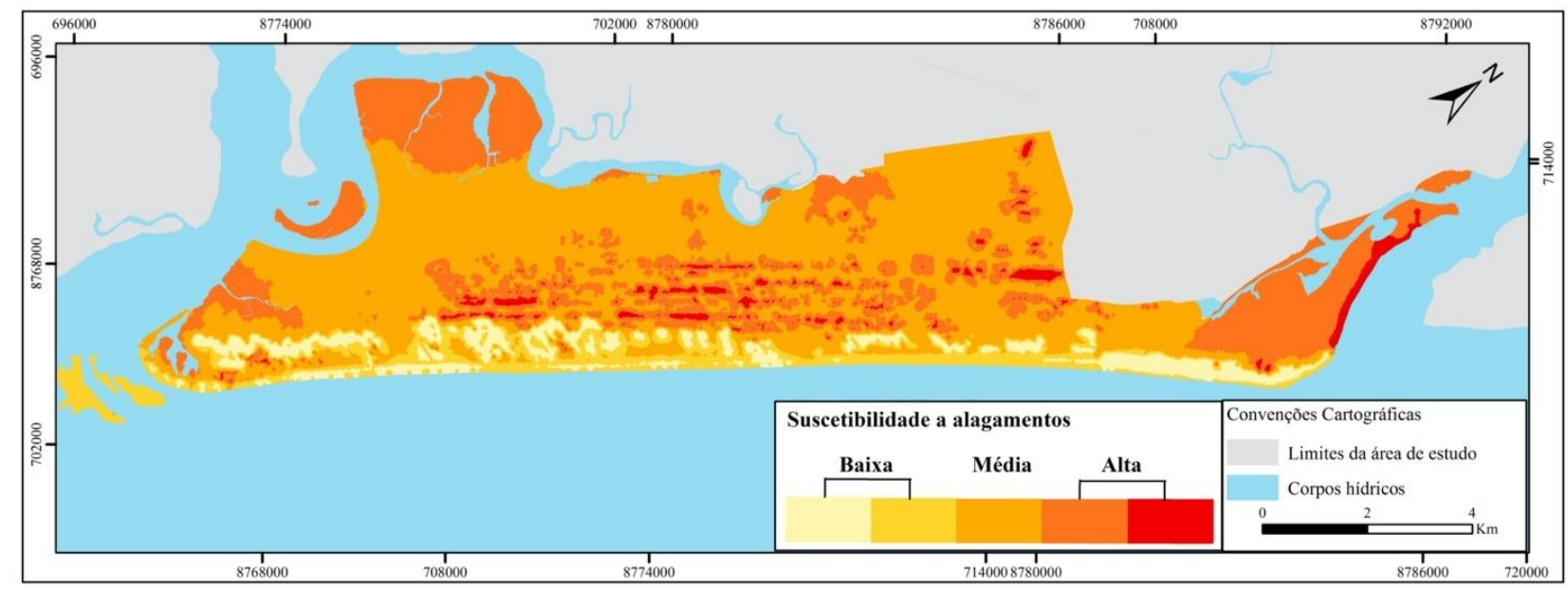

Figura 5: Suscetibilidade a alagamentos da planície costeira de Aracaju/SE. Fonte: Elaboração das autoras, 2020 .

Já os níveis mediados de suscetibilidade aos alagamentos são encontrados na maior porção da área de estudo, associados principalmente as unidades: Terraço Marinho associado aos cordões litorâneos, as Depressões Interdunares, os Depósitos dos Bancos Arenosos Coalescidos, a Planície de Maré e os Ambientes de Sedimentação Recente. Verificou-se que o indicador da cobertura do solo foi determinante para $o$ estabelecimento do grau do mediano. Um exemplo para ilustrar tal situação é a comparação entre o Terraço Marinho e Depósitos dos Bancos Arenosos Coalescidos, uma vez que ambas as unidades possuem uma estruturação natural similar, no entanto, o fato de a ocupação concentrar-se majoritariamente sobre esta última, a torna mais suscetível que o Terraço, em razão da impermeabilização do solo.

Enquadrado no grau alto de suscetibilidade aos alagamentos tem-se: os Baixios úmidos/lagoas, a Planície de Maré, os Depósitos Tecnogênicos e os Depósitos dos Bancos Arenosos Coalescidos. Os Baixios úmidos e lagoas são assim classificados em razão dos pequenos declives que os tornam ambientes receptores dos fluxos de água, circunstância que se soma ao fato de serem alimentadas pelos lençóis subterrâneos, implicando no alagamento permanente de algumas áreas; a Planície de maré insere-se nessa categoria em razão dos solos frequentemente encharcados e da própria composição silto-argilosa; já os Depósitos Tecnogênicos Úrbicos são assim classificados por apresentarem um elevado potencial de retenção superficial da água; e por fim, os Depósitos dos Bancos Arenosos Coalescidos, que adentram tal classificação em razão dos elevados índices de impermeabilização do solo. 


\subsection{Vulnerabilidade a alagamentos da frente litorânea de Aracaju/SE}

Em parte dos estudos que abrangem os riscos, a vulnerabilidade social de uma dada área tende a ser realizada segundo as características da população residente, que revelam a capacidade de resistência e resiliência das comunidades diante de um evento perigoso (CUTTER, 1996, 2012). Via de regra essa avaliação é baseada em matrizes compostas por dados secundários e/ou primários que revelam indicadores sociais como renda, saúde, educação etc.

Obviamente no estudo do risco as particularidades dos ambientes devem ser levados em consideração, e para o caso da área de estudo tais procedimentais foram adaptados, haja vista as particularidades existentes, principalmente no que concerne ao uso do solo. Os dados secundários colhidos não foram suficientes para demonstrar o nível de vulnerabilidade da população, uma vez que os dados referentes à média da renda, a título de exemplo, não conseguia expressar a realidade da área.

Tal situação é justificada pela forma com a qual se deu o processo de uso e ocupação do solo dos bairros citados. Os bairros Coroa do Meio e Atalaia foram concebidos como áreas de reserva à expansão destinadas às classes mais abastadas, plano que não se concretizou pois houve a fixação de população de menor renda ao longo do desenvolvimento dos bairros (FRANÇA; CRUZ, 2005). Já para Zona de Expansão, esse processo é ainda mais evidente. Inicialmente este bairro era ocupado em sua grande maioria por comunidades tradicionais, após a década de 1980 passou a receber o fluxo de moradores de classe médiaalta, incialmente para fins de segunda residência e posteriormente para moradia fixa. Assim, para os três bairros analisados não há predomínio do uso do solo urbano por uma determinada classe social, especialmente na Zona de Expansão, por se tratar de um bairro que reúne desde ocupações de caráter tradicional até condomínios de alto padrão, por vezes, separados por alguns metros de distância.

$\mathrm{Na}$ tentativa de dirimir possíveis erros de interpretação de indicadores sociais, optou-se pela avaliação da vulnerabilidade da população mediante a infraestrutura disponível, em que se avalia a capacidade de suporte.

Tal categorização foi priorizada tendo em vista o perigo relacionado aos alagamentos. Isto porque tende a ocorrer um aumento do grau de exposição da população residente, quando ela está assentada sobre uma área em que os sistemas de drenagem e de esgotamento são falhos; ou, ainda, quando se soma a uma área que possui elevado grau de adensamento, onde a drenagem natural foi alterada ou suprimida, não sucedida da edificação de um novo sistema. $\mathrm{O}$ tipo de esgotamento também foi considerado, uma vez que a ausência de redes coletoras demonstra problemas referentes ao saneamento básico, o que expões mais ainda a população.

Concernente ao sistema de drenagem na Coroa do Meio há apenas uma galeria de concreto, enquanto a Atalaia é bordejada por um canal de drenagem não revestido. Já para a Zona de Expansão a situação é mais gravosa, pois não há canais de drenagem para área. Vale destacar que em decorrência de decisão judicial, em razão da problemática recorrente dos alagamentos, fruto de uma Ação Civil Pública - ACP impetrada pelo Ministério Público Federal, há determinação para implantação e execução em um prazo de oito anos de um sistema de macrodrenagem que atenda ao bairro, sob pena de multas e não autorização para emissão de licenciamento para novos empreendimentos (ACP - MPF, 2009).

No tocante à rede de esgotamento, a Zona de Expansão apresenta preponderância de fossas sépticas e rudimentares, além do descarte em corpos hídricos. A rede geral atende o mínimo de área ocupada. Destacase que esse problema também foi alvo da ACP citada anteriormente. Já nos bairros Atalaia e Coroa Meio a situação é inversa, pois há o predomínio de rede geral em detrimento das fossas rudimentares e sépticas.

Mediante o exposto, a matriz para mensuração da vulnerabilidade foi concebida a partir dos três indicadores citados - nível de derivação da paisagem, rede de esgotamento e rede de micro e macrodrenagem (Tabela 5).

Como já claro nos trechos anteriores, a Zona de Expansão é o único bairro que não apresenta sistema de esgotamento e drenagens aptos a servir minimamente a população, o que manifestamente a inclui no grau de vulnerabilidade muito alto. É notório que o crescimento desse bairro, principalmente após os anos 2000, não foi acompanhado da evolução de infraestrutura necessária ao suporte do contínuo aumento populacional. Além disso, a constante impermeabilização do solo tem alterado o ciclo hidrológico natural, posto que a supressão das lagoas e baixios úmidos tem prejudicado não só a recarga dos lençóis freáticos, mas sobretudo a drenagem natural. Frente à ausência de um sistema eficaz, são estas feições que drenam os excessos pluviais, de forma que a supressão dessas implica em excessivas alterações no escoamento subsuperficial das águas, o que potencializa o escoamento superficial. 
Tabela 5: Vulnerabilidade a alagamentos da Zona de Expansão, Coroa do Meio e Atalaia.

\begin{tabular}{|c|c|c|c|}
\hline $\begin{array}{c}\text { Bairros/ } \\
\text { Indicadores }\end{array}$ & Atalaia & Coroa do Meio & Zona de Expansão \\
\hline $\begin{array}{l}\text { Nível de derivação da } \\
\text { paisagem (NDP) }\end{array}$ & Muito Alto & Muito Alto & Alto \\
\hline Índice & 10 & 10 & 7 \\
\hline $\begin{array}{l}\text { Tipo de esgotamento } \\
\text { (TE) }\end{array}$ & Predomínio de rede geral & $\begin{array}{l}\text { Predomínio de rede } \\
\text { geral }\end{array}$ & $\begin{array}{l}\text { Predomínio de fossas sépticas e } \\
\text { rudimentares (mais de } 70 \% \text { ) }\end{array}$ \\
\hline Índice & 1 & 1 & 7 \\
\hline $\begin{array}{l}\text { Rede de micro e } \\
\text { macrodrenagem } \\
\text { (RMiMa) }\end{array}$ & $\begin{array}{l}\text { Micro e macrodrenagem } \\
\text { existentes com falhas }\end{array}$ & $\begin{array}{c}\text { Apenas } \\
\text { microdrenagem }\end{array}$ & $\begin{array}{l}\text { Micro e macrodrenagem } \\
\text { inexistentes }\end{array}$ \\
\hline Índice & 5 & 7 & 10 \\
\hline $\begin{array}{c}\text { Índice } \\
\mathrm{V}_{\mathrm{ul}}=(0,4 \times \mathrm{NDP})+(0,2 \mathrm{x} \\
\mathrm{TE})+(0,4 \times \mathrm{RMiMa})\end{array}$ & 6,2 & 7 & 8,2 \\
\hline Grau de Vulnerabilidade & Alto & Alto & Muito alto \\
\hline
\end{tabular}

Pondera-se, ademais, que as edificações nas áreas circunvizinhas às lagoas e aos baixios também constituem um problema. Como ambos são abastecidos pelas águas pluviais e freáticas, a zona de inundação habitualmente ultrapassam os limites costumeiros frentes a eventos pluviométricos intensos e constantes, como aqueles observados no outono-inverno. Além disso, a própria impermeabilização nessas adjacências pode ocasionar a maior concentração do fluxo superficial em direção aos baixios e lagoas, promovendo a ampliação das áreas recobertas por água.

Pertinente aos bairros Atalaia e Coroa do Meio, estes são mais bem revestidos de infraestrutura, quando comparado à Zona de Expansão, mas ainda insuficientes frente ao nível de derivação antropogênica da paisagem. Por essa razão ambos os bairros foram enquadrados como de vulnerabilidade alta, justificado pela elevada exposição das ocupações a eventos pluviométricos intensos.

Transpondo as concepções de Wisner et al., (2003), Mendes; Tavares (2009), Mendes et al., (2011) e Cunha (2013) às informações trazidas, constata-se que a causa raiz da vulnerabilidade está associada aos aspectos históricos e políticos, no que concerne à condução de um processo de urbanização desarmônico com as questões sociais e ambientais, o que gerou as condições de insegurança, manifestas na redução da capacidade de suporte dos bairros mediante as situações de maior concentração pluviométrica.

\subsection{Mensuração do risco a alagamentos na planície costeira de Aracaju}

A planície costeira de Aracaju foi classificada segundo os diferentes graus de risco, a partir da interpolação dos dados obtidos e expostos para as variáveis perigo e vulnerabilidade (Tabela 6). As áreas associadas aos diferentes graus de risco estão expostas na Figura 6.

De se notar no mapa exposto que toda a área estudada está associada exclusivamente a dois níveis de risco - médio e alto. Acrescentou-se ainda uma outra classificação não resultante do cômputo dos dados obtidos - as áreas de risco potencial. Este se refere ao tipo de risco que não pode ser definido de forma tão objetiva, portanto de cunho mais qualitativo (CASTRO; PEIXOTO; RIO, 2005). Adentra essa categoria as áreas que são suscetíveis aos alagamentos, mas por não possuírem ocupação, não podem se caracterizar como áreas de risco. Afinal, como destaca Veyret (2013) uma situação para ser considerada de risco tem que envolver necessariamente a presença humana.

Essas áreas de risco potencial perfazem a unidade da Planície de Maré, com destaque ao extenso manguezal presente na Zona de Expansão, o pontal arenoso (popularmente conhecido como praia do Viral) e os bancos arenosos localizados no interior da desembocadura do rio Vaza-Barris. Para fins de planejamento ambiental classificar estes ambientes como de "risco inexistente" pode incorrer numa interpretação errônea sobre a possibilidade de ocupação. Afinal, em ambientes como os citados, o cenário de risco pode emergir assim que se inicie o processo de ocupação. Acrescenta-se, ainda, que por se tratar de um espaço costeiro notadamente marcado por ações especulativas, mesmo não havendo um cenário de risco concreto, é fundamental que se alerte para o fato dessas áreas serem naturalmente frágeis e suscetíveis. 
Tabela 6: Mensuração do risco a alagamentos para Aracaju/SE.

\begin{tabular}{|c|c|c|c|c|c|c|c|}
\hline \multirow{2}{*}{$\begin{array}{c}\text { Unidades } \\
\text { geoecológicas }\end{array}$} & \multirow[b]{2}{*}{ Subunidades } & \multicolumn{3}{|c|}{ Perigo } & \multirow[b]{2}{*}{$\begin{array}{l}\text { Vulnera- } \\
\text { bilidade } \\
\text { (V) }\end{array}$} & \multirow[b]{2}{*}{ 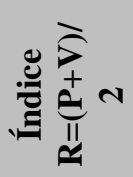 } & \multirow[b]{2}{*}{ Risco } \\
\hline & & $\begin{array}{c}\text { Probabilida- } \\
\text { de/ } \\
\text { Intensidade }\end{array}$ & $\begin{array}{l}\text { Susceti- } \\
\text { bilidade }\end{array}$ & $\begin{array}{c}\text { Índice } \\
(\mathbf{P})\end{array}$ & & & \\
\hline \multirow{3}{*}{ Terraço Marinho } & $\begin{array}{c}\text { Associados a } \\
\text { cordões litorâneos }\end{array}$ & 8 (Alta) & 6 (Média) & 7 & 8,2 (ZE) & 7,6 & Alto \\
\hline & \multirow{2}{*}{$\begin{array}{l}\text { Associados a } \\
\text { baixios } \\
\text { úmidos/lagoas }\end{array}$} & \multirow{2}{*}{8 (Alta) } & \multirow{2}{*}{ 7,8 (Alta) } & \multirow{2}{*}{7,9} & $6,2(\mathrm{~A})$ & 7 & Alto \\
\hline & & & & & 8,2 (ZE) & 8 & Alto \\
\hline \multirow{5}{*}{ Campo de Dunas } & \multirow{3}{*}{ Dunas Frontais } & \multirow{3}{*}{8 (Alta) } & \multirow{3}{*}{$\begin{array}{c}3,5 \\
\text { (Baixa) }\end{array}$} & \multirow{3}{*}{5,8} & $7(\mathrm{CM})$ & 6,4 & Alto \\
\hline & & & & & 6,2 (A) & 6 & Médio \\
\hline & & & & & $\mathbf{8 , 2}(\mathrm{ZE})$ & 7 & Alto \\
\hline & Dunas Fixas & 8 (Alta) & 3(Baixa) & 5,5 & $8,2(\mathrm{ZE})$ & 6,9 & Alto \\
\hline & $\begin{array}{c}\text { Depressões } \\
\text { Interdunares }\end{array}$ & 8 (Alta) & $\begin{array}{c}5,3 \\
\text { (Média) }\end{array}$ & 6,7 & $8,2(\mathrm{ZE})$ & 7,5 & Alto \\
\hline \multirow{2}{*}{$\begin{array}{c}\text { Depósitos dos } \\
\text { bancos arenosos } \\
\text { coalescidos }\end{array}$} & \multirow[b]{2}{*}{ - } & \multirow[b]{2}{*}{8 (Alta) } & \multirow[b]{2}{*}{6,3 (Alta) } & \multirow[b]{2}{*}{7,2} & $7(\mathrm{CM})$ & 7,1 & Alto \\
\hline & & & & & 6,2 (A) & 6,7 & Alto \\
\hline \multirow{7}{*}{ Planície de Maré } & \multirow{2}{*}{ Inframaré } & \multirow{7}{*}{8 (Alta) } & \multirow{7}{*}{6,3 (Alta) } & \multirow{7}{*}{7,2} & $7(\mathrm{CM})$ & 7,1 & Alto $\left(P_{0}\right)$ \\
\hline & & & & & $\mathbf{8 , 2}(\mathrm{ZE})$ & $\mathbf{7 , 7}$ & Alto $\left(P_{0}\right)$ \\
\hline & Supramaré & & & & $7(\mathrm{CM})$ & $\mathbf{7 , 1}$ & Alto $\left(\mathrm{P}_{\mathrm{o}}\right)$ \\
\hline & (apicum) & & & & $\mathbf{8 , 2}(\mathrm{ZE})$ & $\mathbf{7 , 7}$ & Alto $\left(\mathrm{P}_{\mathrm{o}}\right)$ \\
\hline & \multirow{3}{*}{$\begin{array}{l}\text { Supramaré } \\
\text { (manguezal) }\end{array}$} & & & & $7(\mathrm{CM})$ & $\mathbf{7 , 1}$ & Alto $\left(P_{0}\right)$ \\
\hline & & & & & $\mathbf{6 , 2}(\mathrm{A})$ & 6,7 & Alto $\left(\mathrm{P}_{\mathrm{o}}\right)$ \\
\hline & & & & & $8,2(\mathrm{ZE})$ & $\mathbf{7 , 7}$ & Alto $\left(\mathrm{P}_{\mathrm{o}}\right)$ \\
\hline \multirow{5}{*}{$\begin{array}{l}\text { Ambientes de } \\
\text { Sedimentaçãa } \\
\text { Recente }\end{array}$} & \multirow{3}{*}{ Praia/Pós-praia } & \multirow{5}{*}{8 (Alta) } & \multirow{5}{*}{$\begin{array}{c}4,8 \\
\text { (Média) }\end{array}$} & \multirow{5}{*}{6,4} & $7(\mathrm{CM})$ & 6,7 & Alto $\left(\mathrm{P}_{\mathrm{o}}\right)$ \\
\hline & & & & & $\mathbf{6 , 2}(\mathrm{A})$ & 6,3 & Alto $\left(\mathrm{P}_{\mathrm{o}}\right)$ \\
\hline & & & & & $\mathbf{8 , 2}(\mathrm{ZE})$ & $\mathbf{7 , 3}$ & Alto $\left(\mathrm{P}_{\mathrm{o}}\right)$ \\
\hline & Bancos Arenosos & & & & $\mathbf{8 , 2}(\mathrm{ZE})$ & 7,3 & Alto $\left(\mathrm{P}_{\mathrm{o}}\right)$ \\
\hline & Pontal Arenoso & & & & $8,2(\mathrm{ZE})$ & 7,3 & Alto $\left(\mathrm{P}_{\mathrm{o}}\right)$ \\
\hline $\begin{array}{l}\text { Depósitos } \\
\text { Tecnogênicos }\end{array}$ & Material Úrbico & 8 (Alta) & $\begin{array}{l}8,5 \\
\text { (Muito } \\
\text { alta) }\end{array}$ & 8,3 & $7(\mathrm{CM})$ & 7,7 & Alto \\
\hline & $\begin{array}{l}\text { Material de } \\
\text { Dragagem }\end{array}$ & & 6,3 (Alta) & 7,2 & & 7,1 & Alto \\
\hline
\end{tabular}

Legenda: CM (Coroa do Meio); A (Atalaia); ZE (Zona de Expansão); $\left(\mathrm{P}_{0}\right)$ Potencial.

Fonte: Elaboração das autoras, 2020.

Não obstante existirem muitas áreas sem ocupação efetiva dentro da Zona de Expansão, estas não foram classificadas enquanto risco potencial, em razão da influência antrópica indireta, que se apresenta pelas numerosas áreas loteadas.

Pertencente à categoria de grau de risco médio encontra-se restritos setores da área estudada, basicamente aqueles relacionados ao campo de dunas presentes na Coroa do meio e Atalaia, em que prevaleceu a topografia, a composição pedológica e o fato de estarem associadas a dois bairros de melhor infraestrutura.

Já inseridos dentro do grau alto de risco, encontra-se basicamente toda a área estudada. Observa-se que o fato de a Zona de Expansão não possuir infraestrutura adequada, eleva consideravelmente a vulnerabilidade das ocupações aos eventos pluviométricos, o que se tornou um fator determinante. Em razão do processo de interpolação dos dados, dentro do grau alto de risco é possível observar um escalonamento, em que se sobressai as áreas associadas aos baixios úmidos e lagoas. O que de fato chama a atenção para a necessidade premente de preservação dessas unidades a fim de evitar que ocorra o agravamento de uma situação que atualmente já é preocupante. 


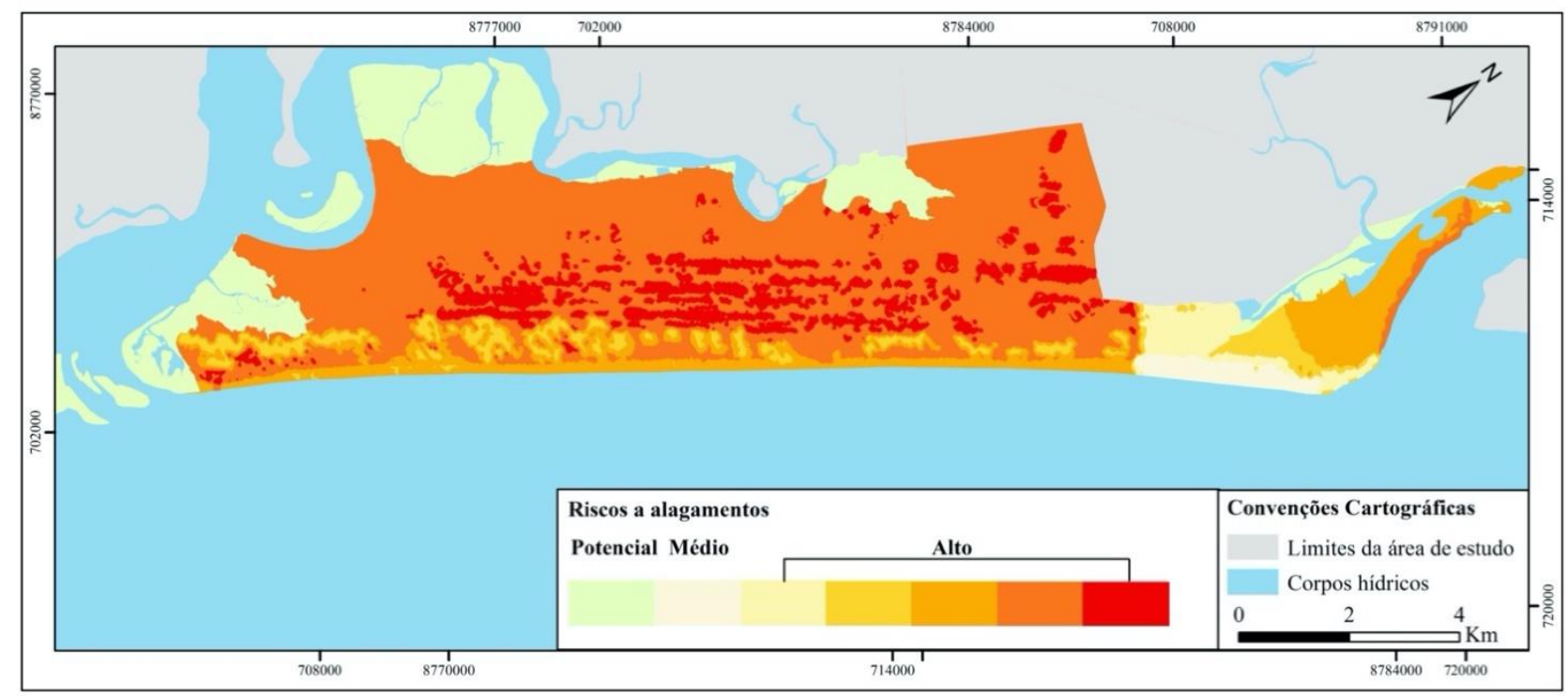

Figura 6: Delimitação das áreas de risco a alagamentos para a planície costeira de Aracaju/SE. Fonte: Elaboração das autoras, 2020.

\section{Conclusões}

Em face do que foi exposto, depreende-se que a forma e a velocidade com a qual se deu o processo de urbanização da frente litorânea de Aracaju não é compatível com o tempo necessário à recuperação das unidades naturais, o que tem ocasionado a redução da capacidade de suporte e resiliência da paisagem. Tal entendimento norteou a concepção de risco aqui utilizado, cuja interpretação esteve pautada na confluência entre os sistemas naturais e sociais, respaldada nos indicadores de perigo e vulnerabilidade.

Frente aos objetivos traçados no presente trabalho, o perigo investigado relacionou-se aos eventos hidrometeorológicos (associados aos alagamentos), concebido a partir da correlação entre probabilidade, magnitude e suscetibilidade. Correlacionado à vulnerabilidade, avaliou-se a capacidade de suporte das estruturas urbanas em confrontação ao perigo citado.

Como consequência do distanciamento entre expansão urbana e planejamento ambiental, sucedeu uma notória carência na rede de infraestrutura urbana, com destaque para ausência de uma rede de macrodrenagem (principalmente na Zona de Expansão), apta a receber os excedentes pluviométricos, cenário este que elevou o grau de vulnerabilidade a alagamentos.

O efeito da combinação entre as situações de perigo e a elevada exposição das ocupações, é a inserção de grande parte da área estudada na classe de risco elevado. Destarte, reitera-se a ideia central desse artigo, em que se considera o risco como produto do rompimento da estruturação natural da paisagem, advindo, primordialmente, das derivações antrópicas. O desequilíbrio resultante, partindo desse princípio, é fruto da alteração da resistência e potencial de resiliência do ambiente. Importante evidenciar que não se trata de determinar que a presença humana necessariamente implicará em situações de desequilíbrios, mas reputar que as relações estabelecidas e as dinâmicas socioeconômicas, nos moldes identificados para Aracaju, por exemplo, são incompatíveis a manutenção de cenário de equilíbrio.

Para o caso das planícies, inseridas na paisagem costeira, esta asserção é ainda mais evidente uma vez que os elementos que a compõem são bastante suscetíveis à ação antrópica e aos próprios eventos naturais. Todo esse cenário ainda é agravado, primeiro por uma falsa sensação de segurança trazida pela constituição plana da paisagem. E, segundo, do ponto de vista do poder público, que por vezes desconsidera o fato da ocorrência de alagamentos ser extremamente corriqueira e causarem prejuízos cotidianos, o que afeta sobremaneira a população mais carente, extremamente afetada por essa conjectura.

Todo esse cenário é visto e revisto sazonalmente em Aracaju, o que reforça a apreensão de que os riscos associados à planície costeira, não obstante menos midiáticos, aditam prejuízos e danos que precisam ser revistos e mitigados. Além disso, devem servir de base para construção de políticas públicas eficientes, tanto na prevenção do risco, como no ordenamento eficaz do uso e ocupação do solo a fim não só de evitar o surgimento de novos cenários de risco, mas também, com o objetivo de conservar as unidades naturais. 
O presente artigo foi fruto da tese de doutorado intitulada "Avaliação geoecológica e dos riscos ambientais na paisagem costeira de Aracaju/SE".

\section{Referências}

CASTRO, S.D.A. Riesgos y peligros: Una isión desde la geografía. Revista Electrónica de Geografía y Ciencias Sociales. n. 60, 55-78, 2000. Disponível em: < http://www.ub.edu/geocrit/sn-60.htm>

BIRD, E. Coastal Geomorphology: an introduction. 2. Ed. New Jersey: Wiley; 2008.

CASTRO, C.M.; PEIXOTO, M.N.O.; RIO, G.A.P. Riscos Ambientais: Conceitualizações, Abordagens e Escalas. Anuário do Instituto de Geociência. n. 2, 11-30, 2005. Disponível em: < http://www.anuario.igeo.ufrj.br/anuario_2005/Anuario_2005_11_30.pdf $>$

CERRI, L. E. S. \& AMARAL, C. P. Riscos Geológicos. In: OLIVEIRA, A. M. S. \& BRITO, S. N. A. (Org.). Geologia de Engenharia. São Paulo: Associação Brasileira de Geologia de Engenharia (ABGE), 1998. p.301310.

CREPANI, E.; MEDEIROS, J.S.; FILHO, P.H.; FLORENZANO, T.G.; DUARTE, V.; BARBOSA, C.C.F. Sensoriamento Remoto e Geoprocessamento Aplicados ao Zoneamento Ecológico - Econômico e ao Ordenamento Territorial. São José dos Campos: INPE, 2001.

CUNHA, L. Vulnerabilidade: a face menos visível do estudo dos riscos naturais. 2013. Disponível em: < http://www.uc.pt/fluc/depgeo/Publicacoes/livro_homenagem_FRebelo/153_165 >. Acesso em: 30 Set. 2015.

CUTTER, S.L. A Ciência da Vulnerabilidade: modelo, métodos e indicadores (Vulnerability Science: Models, Methods, and Indicators). Revista Crítica de Ciências Sociais. p.59, 2012.

CUTTER, S.L. Vulnerability to enviromental hazards. Progress in Human Geography. p. 529-539, 1996.

CUTTER, S.L. Vulnerability to environmental hazards. Progress in Human Geography. 529-539, 1996. DOI: https://doi.org/10.1177/030913259602000407

DAVIS, R.; FITZGERALD, D. Beach and Coasts. Austrália: Blackwell Science Ltd; 2004.

EMBRAPA. Sistema Brasileiro de Classificação de Solos. $2^{\text {a }}$ Edição. Rio de Janeiro; 2006.

FRANÇA, S.L.A.; REZENDE, V.F. A Zona de Expansão Urbana de Aracaju: Dispersão Urbana e Condomínios Fechados. In: Anais do Simpósio Nacional de Geografia Urbana. Belo Horizonte - MG, 2010.

FRANÇA, V.L.A.; CRUZ, M.E. Projeto de Reurbanização da Coroa do Meio: uma estratégia de inclusão social. Revista da Fapese de Pesquisa e Extensão. v.1, p. 43-54, 2005.

FREIRIA, S; CUNHA, L.; SANTOS, N. The importance of natural risks in urban dynamics. In: PANAGOPOULOS, Thomas (Org.) New Models for Innovative Management and Urban Dynamics. University of Algarve, 2009. p.117-127.

GARCIA, R.A.C.; ZÊRERE, J.L. AVALIAÇÃO DOS RISCOS GEOMORFOLÓGICOS: CONCEITOS, TERMINOLOGIAS E MÉTODOS DE análise. In: III Seminário de Recursos Geológicos, Ambiente e Ordenamento do Território. Universidade de Trás-os-Montes e Alto Douro, Portugal, 2003.

GIDDENS, A. As consequências da modernidade. São Paulo: Ed. Unesp; 1991.

HOLLnAGEL, E. The Changing Nature of Risks. Ergonomics Australia Journal, v. 22, 33-46, 2008. Disponível em: < https://www.ergonomics.org.au/documents/item/223 >

IBGE. Censo Demográfico. 2010. Disponível em: http://censo2010.ibge.gov.br/. Acesso em: 16 mai. 2016. 
IBGE. Manual Técnico de Pedologia. 2. ed. Rio de Janeiro: 2007.

BGE. Panorama das cidades. 2019. Disponível em: https://cidades.ibge.gov.br/brasil/se/aracaju/panorama. Acesso em: 18 fev. 2020.

INMET. Banco de Dados Meteorológicos para Ensino e Pesquisa. Disponível em: http://www.inmet.gov.br/portal/index.php?r=bdmep/bdmep. Acesso em: 4 jun. 2016.

JONES, D. Environmental hazards in the 1990s: problems, paradigms and prospects. Geography. n.2, 161$165,1993$.

MACHADO, E.V. Aracaju: "Paisagens e Fetiches". Abordagens acerca do processo de seu crescimento urbano recente. Dissertação de Mestrado. UFSC, Santa Catarina, 1989.

MENDES, J.M.; TAVARES, A.O.; CUNHA, L.; FREIRIA, S. A vulnerabilidade social aos perigos naturais e tecnológicos em Portugal. Revista Crítica de Ciências Sociais. v. 93, 95-128, 2011.

MENDES, J.M.; TAVARES, A.T. Building resilience to natural hazards. Practices and polices on governance and mitigation in the central region of Portugal. Safety, Reliability, and Risk Analysis: Theory, Methods and Applications. London: Taylor \& Francis Group. 1557-1584, 2009.

MINISTÉRIO PÚBLICO FEDERAL - SERGIPE. TRF 5. Seção judiciária de SE. $1^{\text {a }}$ vara federal. ACP ${ }^{\circ}$ 0002637-41.2009.4.05.8500. Ano de ajuizamento: 2009. Em tramitação.

MMA - MINISTÉRIO DO MEIO AMBIENTE. Projeto Orla: fundamentos para gestão integrada. Brasília: Ministério do Meio Ambiente e Ministério de Planejamento, Orçamento e Gestão, p. 78, 2002.

MONTEIRO, C.A.F. Geossistemas: a história de uma procura. 2. ed. São Paulo: Editora Contexto; 2001.

MOTA, L.S.O.; SOUZA, R.M. Análise evolutiva e caracterização dos depósitos tecnogênicos associados ao bairro Coroa do Meio, Aracaju/SE. Quaternary and Environmental Geosciences. n. 2, 01-09, 2018. DOI: http://dx.doi.org/10.5380/abequa.v9i2.53373

MOTA, L.S.O.; SOUZA, R.M. Análise Geoecológica da Paisagem Costeira do Município de Aracaju/Sergipe. Ra'e Ga. v. 42, 86-103, 2017. DOI: http://dx.doi.org/10.5380/raega.v42i0.45923

NOGUEIRA, A.D. Análise Sintático-Espacial das Transformações Urbanas de Aracaju (1855-2003). Tese de Doutorado. UFBA, Salvador, 2004.

PEDUZZI, P. The disaster risk, global change, and sustainability nexus. Sustainability. n.11, 1-21, 2019. DOI: https://doi.org/10.3390/su11040957

RIBEIRO, N.M.G. Transformações Recentes no Espaço Urbano de Aracaju. Revista Geonordeste., n.1, 20$31,1985$.

RODRIGUEZ, J.M.M.; SILVA. E.V.DA; CAVALCANTI, A.P.B. Geoecologia das Paisagens: Uma visão geossistêmica da análise ambiental. Fortaleza: Editora UFC; 2004.

SMITH, J.B.; FITZGERALD, D.M. Sediment Transport Patternes. Journal of Coastal Research. v. 10, n. 3, 1994.

SMITH, K.; PETLEY, D.N. Environmental Hazards: Assessing Risk and Reducing Disaster. London and New York: Routledge; 1991.

UNDRO (ONU). Natural Disasters and Vulnerability Analysis. 1979. Disponível em: http://www.unisdr.org/files/resolutions/NL800388.pdf. Acesso em: 23 out. 2015. 
VEYRET, I. Os Riscos: o homem como agressor e vítima do meio ambiente. 2. ed. São Paulo: Editora Contexto; 2013.

VILAR, J.W.C. A Zona de Expansão de Aracaju: Contribuição ao Estudo da Urbanização Litorânea de Sergipe. In: VILAR, J.W.C.; ARAÚJO, H.M. de. Território, Meio Ambiente e Turismo no Litoral Sergipano. São Cristóvão: Ed. UFS, 2010.

WHITE, G. Natural Hazards: local, national, global. New York: Oxford University Press; 1974.

WISNER, B.; BLAIKIE, P.; CANNON, T.; DAVIS, I. At Risk: natural hazards, people's vulnerability and disasters. 2. ed. New York: Routledge; 2003.

(1) 